\title{
1. Introduction to the Handbook of Research Methods for Organisational Culture
}

\author{
Cameron Newton
}

Organisational culture continues to be the pervasive force in organisations of all types, sizes, and objectives. If it is misaligned with organisational strategic objectives, the chances of achieving those objectives are greatly diminished. Schein (1996) referred to organisational culture as an influential force: stable and powerful. Over the years, organisational culture has been defined in hundreds of different ways, some more sophisticated than others. Schein (1985) contributed greatly to the debate around definitions of organisational culture, describing it as a layered phenomenon composed of inter-related levels of meanings. These can range from meanings that are mostly invisible, to those that are observable, and include basic assumptions that people share, values (governing rules and beliefs), and artefacts (the visible or tangible aspects). However, from here, researchers have diverged and used different methods and tools to explore and understand organisational culture. This Handbook highlights the varied approaches and challenges associated with researching and measuring organisational culture. Moreover, this collection of works from talented researchers highlights the need to continue to unpack and understand organisational culture, to meaningfully influence the future effectiveness and efficiency of organisations of all types across the globe.

\section{OUTLINE OF THE HANDBOOK}

This Handbook has been arranged in three parts representing the conceptual and definitional issues, measurement approaches, and contextual issues surrounding research of organisational culture.

\section{PART I: CONCEPTUAL ISSUES RELATING TO ORGANISATIONAL CULTURE}

In Chapter 2, Penny Williams explores the definitions, distinctions and functions of organisational culture, unpacking the values, norms and deeply held beliefs of employees, and the artefacts visible in corporate practices, statements, and symbols. She explores the value of organisational culture and its links to varied organisational outcomes. In Chapter 3, Athena Xenikou focusses on the role of leaders in organisational culture. She examines the nature of the relationship between leadership and organisational culture by initially delving into the mechanisms that leaders have at their disposal to formulate, reinforce, and change their organisation's culture depending on its developmental stage. Further exploring leadership as an antecedent of culture, and the mediating effect of culture in the leadership-organisational outcomes link, she examines culture as a social process activated by leaders to influence 


\section{Handbook of research methods for organisational culture}

various aspects of organisational behaviour. In Chapter 4, Kamarul Zaman Bin Ahmad looks at the research relating to fit and congruence with organisational culture, and the definitional and measurement issues from this perspective. Last in Part I, Ronald Fischer, Johannes Karl, Gerard Janse van Rensburg, and Maria Cristina Ferreira explore multi-level issues in organisations and culture. They examine the complex phenomenon of cultures embedded within larger cultural systems, including national culture. Further, they explore the theoretical and methodological issues of culture at both organisational and national level and how they are interlinked.

\section{PART II: QUANTITATIVE AND QUALITATIVE APPROACHES}

Part II of the Handbook examines the varying methodological approaches to research of organisational culture. In Chapter 6, Stefano Calciolari and Anna Prenestini take a values-based perspective, analysing two different types of approaches - typological and dimensional - looking closely at the Competing Values Framework and the Organizational Culture Inventory ${ }^{\circledR}$. In Chapter 7, Jennifer Chatman and Andrew Choi focus on establishing field-wide construct validity for measures of organisational culture, addressing the challenge of defining organisational culture and evaluating measurement options that, considered in conjunction, can increase construct validity and accessibility to relevant data while reducing various biases. In Chapter 8, Alireza Javanmardi Kashan and Anna Wiewiora take an extensive look at the commonly used qualitative approaches to researching organisational culture as well as the analytical and theory-building approaches used in qualitative studies. The chapter highlights the importance of alignment between assumptions about organisational culture and the methods and approaches used for studying it, and guides the researcher through the steps of designing qualitative studies on organisational culture, data collection methods and analysis, coding methods and theory-building approaches. Last in this part, Roslyn Cameron and Leesa Taylor focus on the use of mixed-methods research in measuring organisational culture, exploring definitional and methodological issues.

\section{PART III: SPECIAL TOPICS OF ORGANISATIONAL CULTURE MEASUREMENT}

Given the complexity associated with organisational culture, it is not surprising that the special topics part of the book is significant, including ten distinct chapters. In Chapter 10, Julian Randall addresses the difficult and contentious topic of cultural change, examining models and then taking a more qualitative and case-based perspective in exploring change. In Chapter 11, Adelle Bish explores more closely the multiple challenges involved with defining and measuring high-performance culture, concluding with a proposed framework that identifies questions to consider as part of the research design phase. In Chapter 12, Jay Rao and Shelby Danks take a detailed look at an enterprise culture of innovation. The authors overview some key instruments from the literature that define and assess an organisational culture of innovation, and present the InnoQuotient Model as an example of a practitioner-oriented measurement model for such assessment. Following on from this, Jenna Campton's Chapter 13 addresses the challenges associated with researching, measuring, and building corporate entrepreneurship cultures and the process of entrepreneurial activity within an organisation. She takes a critical 
look at research in this emerging area and the challenges associated with conceptualising and measuring this construct.

Niel Christensen, Nathanael Lee, and John Bingham, in Chapter 14, explore the measurement and development of ethical organisational culture. The authors examine current methods and research approaches to the study of ethical climate and propose a nomological categorization of existing antecedents as well as suggesting tools for practitioners and researchers seeking to measure ethical climate. In Chapter 15, Ruth Knight examines various issues particularly related to nonprofit organisational cultures, including the role and impact of nonprofit organisational culture on organisational and employee outcomes, measurement issues, and the emerging topic of philanthropic culture. Continuing the nonprofit theme, in Chapter 16, Adelle Bish, Karen Becker, and Bernd Irmer take a comparative case study approach to exploring the role of leadership capabilities in the context of nonprofit organisational culture influence.

Perhaps the most resilient of our contributors, Sonja Sackmann, in Chapter 17 ventures into the depths of deciphering bad organisational cultures. She discusses the critical issues associated with analysing 'bad' cultures in terms of being corrupt or unethical, before exploring various data collection methods that can be used for deciphering corrupt or unethical cultures, including their strengths and challenges. In Chapter 18, Angela Ward examines the issues around measurement of organisational culture in Christian churches, including the unique organisational qualities of the church, how these qualities affect the measurement of organisational culture, and how these may be quantified to aid culture measurement.

Last, in Chapter 19, Tristan Casey, Xiaowen Hu, Chantelle Reid, Phuong Anh Tran, and Frank Guldenmund discuss the often studied, yet poorly understood (or measured) concept of safety culture. The authors bring conceptual and methodological clarity with a particular focus on definitional-methodological alignment. A safety culture 'manifesto' is presented in the hope that it can guide future research on safety culture by advancing commitments that researchers can uphold.

Overall, this Handbook represents a valuable opportunity to reflect on the complexity and the advancement of organisational culture research over time, and the new ways and contexts that we need to be aware of as we continue to create meaningful impact.

\section{REFERENCES}

Schein, E. H. (1985). Organizational Culture and Leadership: A Dynamic View. San Francisco: Jossey-Bass.

Schein, E. H. (1996). Culture: The missing concept in organization studies. Administrative Science Quarterly, 41, 229-240. 